\title{
Mitochondrial phylogeography of rock-dwelling cichlid fishes reveals evolutionary influence of historical lake level fluctuations of Lake Tanganyika, Africa
}

\author{
ERIK VERHEYEN ${ }^{1}$, LUKAS RÜBER ${ }^{1,2,3, *}$, JOS SNOEKS ${ }^{4}$ \\ AND AXEL MEYER ${ }^{3}$ \\ ${ }^{1}$ Section of Taxonomy and Biochemical Systematics, Royal Belgian Institute of Natural Sciences, Vautierstraat 29, 1040 \\ Brussels, Belgium \\ ${ }^{2}$ Zoological Museum of the University of Zürich, Winterthurerstrasse 190, 8057 Zürich, Switzerland \\ ${ }^{3}$ Department of Ecology and Evolution, State University of New York, Stony Brook, New York 11794-5245, U.S.A. \\ ${ }^{4}$ Vertebrate Section, Africa Museum, Leuvense-steenweg 13, 3080 Tervuren, Belgium
}

\section{SUMMARY}

The East African Lakes Tanganyika, Malawi and Victoria each harbour hundreds of endemic invertebrate and vertebrate species. Inferences about the ecological and evolutionary processes responsible for the origin of these species flocks will only be possible when they are made within historical and comparative frameworks. Specifically, the relative importance of intrinsic characteristics and extrinsic factors may offer information about the processes that drive diversification and speciation in these species. We investigated the sequence variation of a segment of the mitochondrial DNA control region of 32 populations representing all four nominal species in the three genera of eretmodine cichlids from Lake Tanganyika. Based on a phylogenetic analysis of these data we attempted to evaluate the importance of major lake level fluctuations on patterns of intralacustrine speciation. The geography of genetic variation reveals a high degree of within-lake endemism among genetically well-separated lineages distributed along the inferred shore lines of three historically intermittent lake basins. Seismic data indicate that extreme lowering of water levels in the Pleistocene caused the single Lake Tanganyika basin to split into three isolated ones. The strong phylogeographic structure of the Eretmodini, and the observation that some closely related populations occur on opposite shores of the lake, agree with this geological scenario. The three-clade-three-basin phylogeographic pattern was repeated twice within this tribe of cichlids. The phylogeographic pattern of eretmodine cichlids suggests that major fluctuations in the level of the lake have been important in shaping their adaptive radiation and speciation. The mitochondrially defined clades are in conflict with the current taxonomy of the group and suggest that there has been convergent evolution in trophic morphology, particularly in the shapes of oral teeth, taxonomically the most diagnostic characters of the three genera.

\section{INTRODUGTION}

In 1895, the Royal Society financed a scientific expedition led by J. E. S. Moore to the East African lakes, including Lake Tanganyika (Moore 1903). By that time it had already become apparant that the endemic cichlid fish faunas of the East African Lakes are biologically astonishingly diverse and distinct from each other, each containing hundreds of species. Even today these species flocks are viewed as the most spectacular example among living vertebrates of evolutionary phenomena such as adaptive radiation and explosive speciation (Fryer \& Iles 1972; Futuyma 1986; Coulter 1991; Martens et al. 1994). The three East African Lakes: Tanganyika, Malawi, and Vic-

* Present address: Department of Ecology and Evolution, State University of New York, Stony Brook, New York 11794-5245, U.S.A. toria each harbour hundreds of endemic invertebrate and vertebrate species providing ample opportunity for the study of the evolutionary mechanisms that might be responsible for the formation of species flocks (Fryer \& Iles 1972).

Probably due to its greater age, the Tanganyikan cichlid species flock is morphologically and behaviourally more diverse than the flocks of Lakes Malawi and Victoria (Fryer \& Iles 1972) although it harbours the lowest number of endemic cichlid species (more than 170; but see Snoeks et al. 1994). With an estimated age of 9-12 Ma, Lake Tanganyika is considerably older than Lakes Malawi and Victoria (Cohen et al. 1993). Its species are therefore likely to be on average older and hence more genetically distinct. This makes molecular phylogenetic work on Tanganyika cichlids more feasible than on the younger species of Lakes Malawi and Victoria (Meyer et al. 1990; Meyer $1993 b)$. Questions about the evolution of cichlid fishes 
can be addressed with molecular phylogenetic techniques that avoid the potential pitfalls of morphological homoplasy, due to convergent evolution, in reconstructing their evolutionary relationships (e.g. Meyer $e t$ al. 1990; Sturmbauer \& Meyer 1992, 1993; Klein et al. 1993; Kocher et al. 1993; Moran \& Kornfield 1993; Sturmbauer et al. 1994; Sültmann et al. 1995).

The great majority of the cichlid fish species of Lake Tanganyika are confined to the patchy rocky habitats that are separated by sandy beaches along its shorelines (Brichard 1989). Most cichlids have restricted geographic distributions within their respective lakes, and only a very small number of species is found lake-wide (Fryer \& Iles 1972; Brichard 1989; Snoeks et al. 1994). Molecular studies indicate that rock-dwelling cichlid species in Lakes Malawi and Tanganyika are usually strongly subdivided into genetically distinguishable populations (e.g. Sturmbauer \& Meyer 1992; Bowers et al. 1994; Moran \& Kornfield 1995). Their typically high habitat specificity, site fidelity, and low capacity for dispersal are all expected to reduce gene flow between populations, and to be at least partly responsible for the extensive intralacustrine allopatric speciation. The high speciation rates in rock-dwelling cichlids are believed to be driven by both intrinsic (e.g. stenotopy and sexual selection) and extrinsic factors, such as vicariant biogeographical processes that restrict gene flow between (micro)allopatric populations (Sturmbauer \& Meyer 1992; Meyer 1993 b; Ribbink 1994). Intralacustrine allopatric speciation involving spatial isolation, either by basin subdivision or intralacustrine microallopatric segregation, has been invoked as the most important mode of speciation in cichlid species flocks (Brooks 1950; Poll 1951; Ribbink 1986; Coulter 1991; Meyer 1993b). Yet the occurrence of locally restricted sister taxa could also indicate sympatric speciation, as suggested for two small cichlid species flocks endemic to crater lakes in Cameroon (Schliewen et al. 1994).

Geological evidence indicates that approximately 200000 years ago periods of aridity persisting for several thousand years have caused dramatic drops up to $600 \mathrm{~m}$ - in water level splitting Lake Tanganyika into three separate lakes (Tiercelin \& Mondeguer 1991). So far, only a few studies support the hypothesis that lake-wide phylogeographic patterns, and possibly the process of speciation itself, is associated with abiotic historical events such as lake level fluctuations (Greenwood 1964; Owen et al. 1990; Sturmbauer \& Meyer 1992). A recent study of the Tanganyikan rockdwelling cichlid genus Tropheus showed that the amount of genetical differentiation among neighbouring Tropheus populations can be either large or small, depending on the sampling localities in the lake (Sturmbauer \& Meyer 1992). The intralacustrine distribution of mitochondrial DNA (mtDNA) haplotypes in Tropheus provides some evidence that major fluctuations in lake level have played a dominant role in determining population genetic structure, and possibly speciation, in rock-dwelling cichlids of Lake Tanganyika (Sturmbauer \& Meyer 1992). However, the capacity to disperse, to defend breeding and feeding territories, the size of broods, and other life history characteristics may also influence the genetic population structure, and thus be important in determining modes of speciation (Fryer \& Iles 1972; Meyer et al. 1996).

To test further the relative importance of biotic and abiotic factors, additional comparative phylogeographic data are needed. Here we investigate the variation in the mtDNA control region of cichlids of the tribe Eretmodini (Poll 1986). This tribe comprises four nominal species, assigned to three genera: Eretmodus cyanostictus Boulenger 1898; Spathodus erythrodon Boulenger 1900; Spathodus marlieri Poll 1950; and Tanganicodus irsacae Poll 1950. These cichlids have, among lake cichlids, a uniquely reduced swimbladder that allows them to live in shallow gravel and rocky shores in the surge zone of Lake Tanganyika. Limited dispersal ability probably contributed to the formation of several allopatric colour morphs of these morphologically very similar taxa (Konings 1988; Brichard 1989). The shape of the mandibular teeth is the main defining taxonomic character and is of considerable ecological consequence to their feeding behaviour. The teeth of Eretmodus are spatula-shaped with a slender neck region, those of Spathodus are shaped with a flattenend and truncated crown, and those of Tanganicodus are slender and pointed. These differences in dental morphology (and also the position of the mouth and the morphology of the dental arcade) are causally linked to trophic differences. Tanganicodus is an invertebreate 'picker' whereas Eretmodus and Spathodus mainly scrape algae off rocks (Yamaoka et al. 1986; Yamaoka 1987).

\section{MATERIALS AND METHODS}

(a) Species, populations and gene studied

A total of 43 specimens from 32 localities was studied. The fish were collected, during two expeditions in 1991 and 1992, along the Burundian and Tanzanian costline of Lake Tanganyika (figure 1). Coordinates of localities were determined using a Global Positioning System (GPS). Additional specimens were provided by Heinz H. Büscher and Luc De Vos. Specimens were fixed in $75 \%$ ethanol and muscle tissue samples were dissected and stored at $-80^{\circ} \mathrm{C}$. All voucher specimens have been deposited in the Africa Museum at Tervuren (Belgium). The specimens were identified using the criteria of Poll (1986). However, it is clear from our study that the taxonomy might be in need of revision (L. Rüber et al., unpublished data). 336 base pairs (b.p.) of the mt control region were determined (EMBL accession numbers X90593-X90638). When specimens yielded unexpected phylogenetic affinities on the basis of their mtDNA sequences, they were reexamined, DNA was reextracted, amplified and resequenced, to eliminate the possibility of contamination and/or mixing up of vials during the manipulations.

\section{(b) DNA extraction, PCR and nucleotide sequencing}

DNA was isolated from muscle tissue using standard proteinase $\mathrm{K}$ digestion and phenol extraction (Kocher et al. 1989). The primers used to amplify a portion of 


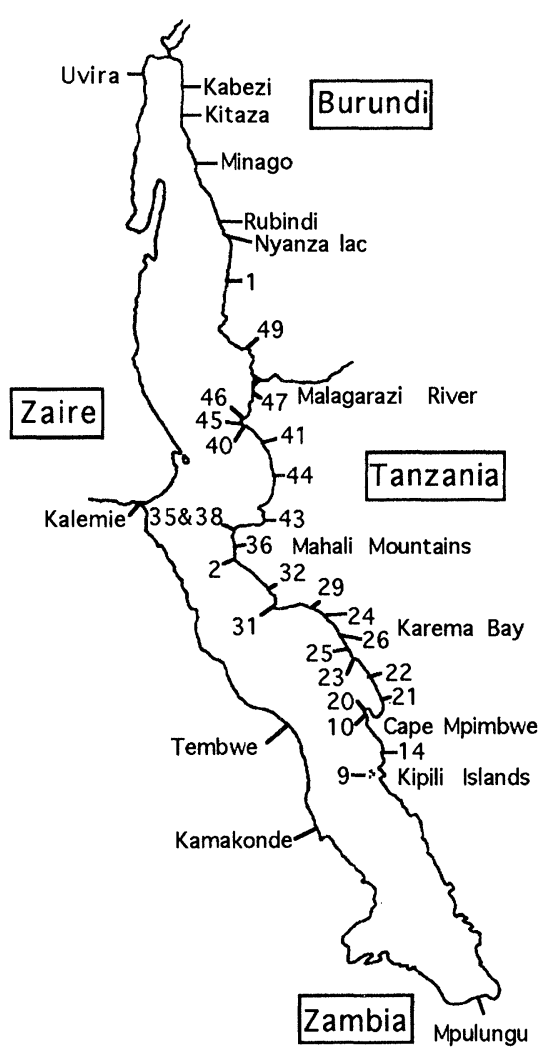

Figure 1. Map of Lake Tanganyika showing all the localities and sample sites mentioned in the text. Lake Tanganyika is about $650 \mathrm{~km}$ in length and maximally $80 \mathrm{~km}$ wide.

the proline tRNA and a segment of the control region were L15995 (Meyer et al. 1994.) and H16498 (Meyer et al. 1990) using protocols given in Kocher et al. (1989), and Meyer et al. (1990, 1994). Approximately $0.15-0.20 \mu \mathrm{g}$ of the double-stranded polymerase chain reaction (PCR) product was cycle-sequenced according to the manufacturer's protocol (Pharmacia), using $0.8 \mu \mathrm{M}$ primer and 2.5 units of $\mathrm{T}$ th polymerase. Only the L-primer was used for the cycle sequencing reaction. The temperature profile for cycle sequencing was denaturation at $95^{\circ} \mathrm{C}$ for $36 \mathrm{~s}$, annealing at $52{ }^{\circ} \mathrm{C}$ for $36 \mathrm{~s}$ and extension at $72{ }^{\circ} \mathrm{C}$ for $80 \mathrm{~s}$. After 25 cycles the samples were kept at $72^{\circ} \mathrm{C}$ for 5 min before they were analysed on an ALF-DNA Sequencer (Pharmacia).

\section{(c) Phylogenetic analyses}

The sequences were aligned by eye and were analysed by means of the parsimony method using PAUP (version 3.1.1; Swofford 1993). Neighbourjoining analyses (Saitou \& Nei 1987) were performed using MEGA (version 1.01, Kumar et al. 1993). For more details on the phylogenetic analyses see figure legends. Confidence estimates were obtained using the bootstrap method (Felsenstein 1985). Tropheus duboisi was declared as an outgroup based upon a phylogenetic analysis of the major mouthbrooding lineages of Lake Tanganyika (Sturmbauer \& Meyer 1993).

\section{RESULTS}

\section{(a) Sequence variation in the control region}

Only one 2 b.p. insertion/deletion event was found. Eighty-one positions $(24 \%)$ contain variation (figure 2). Several conserved regions without nucleotide variation were observed (e.g. Saccone et al. 1987). The overall base compositions within the Eretmodini exhibits an anti $\mathrm{G}-\mathrm{C}$ bias in the control region, a trait characteristic of vertebrate mtDNA (Meyer 1993a). Even among the most diverged lineages within the Eretmodini transitions outnumber transversions, indicating that the transitions still contain phylogenetic information (DeSalle et al. 1987).

\section{(b) Age estimates for the Eretmodini sequence variation}

The maximum corrected (Kimura 1980) sequence divergences within the Eretmodini were compared with those that had been found within other Lake Tanganyika cichlids (recalculated for the published sequences): the Ectodini, the Lamprologini and the genus Tropheus (Sturmbauer \& Meyer 1992, 1993; Sturmbauer et al. 1994). The calculated divergences are based on all substitutions and also on transversions only (given in brackets); Lamprologini: $22.7 \%$ $(11.0 \%)$; Ectodini: $15.7 \%(7.4 \%)$; Eretmodini: $12.5 \%(5.2 \%)$; Tropheus: $16.1 \%(4.7 \%)$. Assuming a comparable rate of molecular divergence among these lineages, the maximum observed corrected sequence divergence within three other Tanganyikan cichlid lineages indicates that the Eretmodini are approximately $0.5-0.8$-fold as old as suggested for the Lamprologini and the Ectodini, and approximately the same age as the genus Tropheus (Sturmbauer \& Meyer 1992).

\section{(c) Phylogeny of the tribe Eretmodini}

Two major mt lineages within this tribe (symbolized by $\mathrm{A}$ and $\mathrm{B}$ in figures 2, 3 and 4 ) were identified. Lineage A containes three clades, Al-A3, and lineage B containes four clades, B1-B4. The evolutionary relationships within the Eretmodini are corroborated by both parsimony (Swofford 1993) and neighbourjoining (Saitou \& Nei 1987) methods, and most branches defining the major clades are supported with high bootstrap confidence (Felsenstein 1985) (see figures 3 and 4). Differences between the parsimony and the neighbour-joining method are limited to the relative placement of the clades within lineage $B$ (figures 3 and 4 ). In the parsimony trees, clade $\mathrm{B} 1$ is sistergroup to $\mathrm{B} 2+\mathrm{B} 3+\mathrm{B} 4$, wheras in the neighbourjoining tree $\mathrm{B} 4$ is sistergroup to $\mathrm{B} 1+\mathrm{B} 2+\mathrm{B} 3$. However, the relative positions of the four clades within the $\mathrm{B}$ lineage are not supported by high bootstap values (L. Rüber et al., unpublished data).

The current generic classification within the Eretmodini is in partial conflict with the mtDNA phylogeny, and may be in need of revision (figures 3 and 4). Clades Al and B4 contain mtDNA haplotypes from all three genera. The taxonomic and phylogenetic implications, and the evolution of dentitional dif- 


\begin{tabular}{|c|c|c|}
\hline Erotmodini & $\begin{array}{r}1111111111111111111111111111111122222222222222223333333 \\
244444677778888899999999001222233334445555666666567777778812344555555567990122233 \\
10168934890123401234678271234723457892378024567890256893882589123456726584768905\end{array}$ & Clade \\
\hline 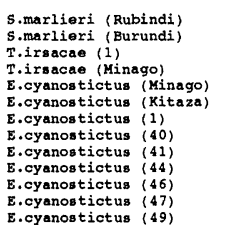 & 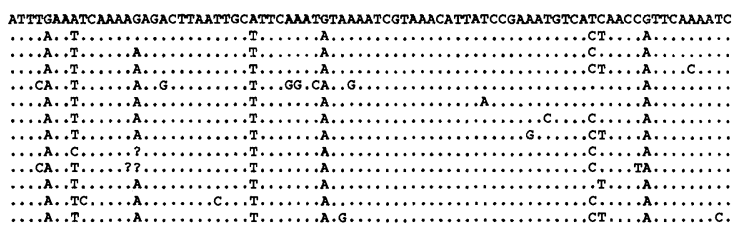 & A] \\
\hline $\begin{array}{ll}\text { E. cyanostictus } & (2) \\
\text { E.cyyanostictus } & (36) \\
\text { E.cyanostictus } & (38)\end{array}$ & 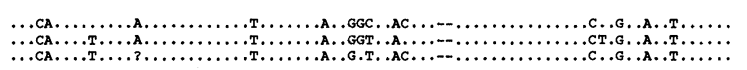 & A2 \\
\hline 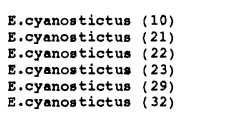 & 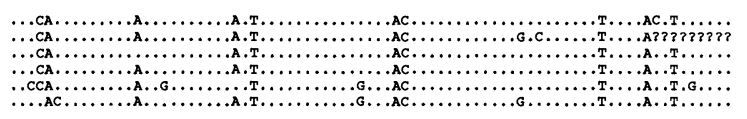 & A3 \\
\hline $\begin{array}{l}\text { S.erythrodon (Kabezi) } \\
\text { S.erythrodon (Minago) } \\
\text { S.erythrodon (49) }\end{array}$ & 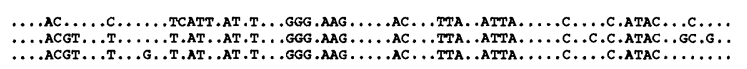 & B1 \\
\hline 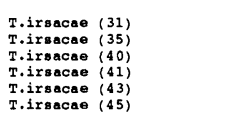 & 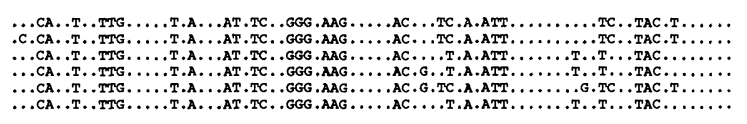 & B2 \\
\hline $\begin{array}{ll}\text { S.erythrodon (Tembor) } \\
\text { S.erythrodon } \\
\text { S.erythrodon } \\
\text { S.erythrodon } \\
\text { S.ery) } \\
\text { S.erythrodon } \\
(26)\end{array}$ & 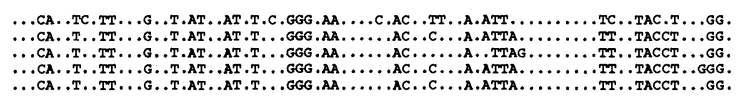 & B3 \\
\hline 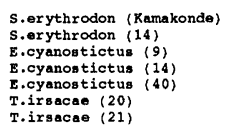 & 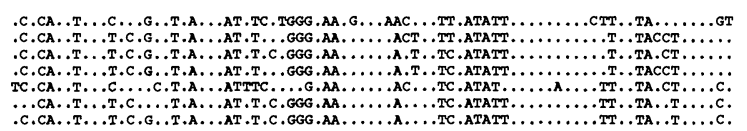 & B4 \\
\hline
\end{tabular}

Figure 2. Variable sites in a 336 b.p. section of the control region in the tribe Eretmodini. The $(-)$ denotes a gap. The following sequences are identical: T. irsacae (40) and T. irsacae (45); S. erythrodon (23) and S. erythrodon (26). Numbers indicate sampling localities (see figure 1).

ferences within the Eretmodini, will be discussed elsewhere (L. Rüber et al., unpublished data).

\section{(d) Sequence divergence within the Eretmodini}

Based on the phylogenetic analyses, seven genetically distinct clades within two major lineages were identified (figures 3 and 4). The estimated genetic divergences within the three clades from lineage A are small and similar (mean about $1.3 \%$ ), suggesting that these radiations originated relatively recently, and simultanously, in a 'secondary radiation' (figure 3). The average corrected sequence divergences between the clades within lineage A are also rather similar (ca. $3.1-3.4 \%$ ) and indicate that the A-clades are also about of the same age and might have occurred in a 'primary radiation' of the A-lineage. The estimated genetic divergences within clades from lineage $\mathrm{B}$, however, are higher and more variable (means range from $1.3-3.2 \%$; figure 3 ) hinting that those clades are of different evolutionary ages and might not have radiated within as short a time span as the clades within the A-lineage. The higher average corrected sequence divergence $(4.5-7.7 \%$ ) observed between the $\mathrm{B}$-clades indicate that the B-lineage is considerably older than the A-lineage.

\section{(e) Intralacustrine distribution of mtDNA clades}

The three clades Al-A3 show a non-overlapping phylogeographic pattern along the eastern shore of Lake Tanganyika (figure $5 a$ ). Clade Al is widely distributed and ranges from Burundi to the northern edge of the Mahali Mountain area. Clade A2 is restricted to the Mahali mountain area in the central part of the lake. Clade A3 ranges from the southern edge of the Mahali mountain area to Cape Mpimbwe.

The four clades within the B-lineage also show restricted and non-overlapping geographic distributions (figure $5 b$ ). Clade Bl only contains specimens of $S$. erythrodon, and ranges from Burundi to north of the Malagarazi river delta. Glade B2, which consists exclusively of $T$. irsacae, is only found south of the Malagarazi river delta. The southern-most range of this clade is the southern edge of the Mahali mountain area. Another clade (B3) containing S. erythrodon is found around the Karema Bay and in Tembwe on the opposite western shore line. Clade B4 is morphologically heterogeneous and contains individuals classified as Spathodus, Eretmodus and Tanganicodus. Its distribution ranges from slightly north of Cape Mpimbwe to the Kipili Islands, the southern end of the sampling area, and Kamakonde on the western shore of the lake (figure $5 b$ ).

Specimens that belong to the two most inclusive phlylogenetic lineages, $\mathrm{A}$ and $\mathrm{B}$, live sympatrically along nearly the whole length of the regions collected. It seems worth pointing out that where the members of the two lineages co-occur they generally have different tooth shapes and hence different trophic ecologies, and hence are identified as different genera. The geographic distributions of each clade (A1 and B1, etc) in the two lineages are similar (figures $5 a, b)$. 


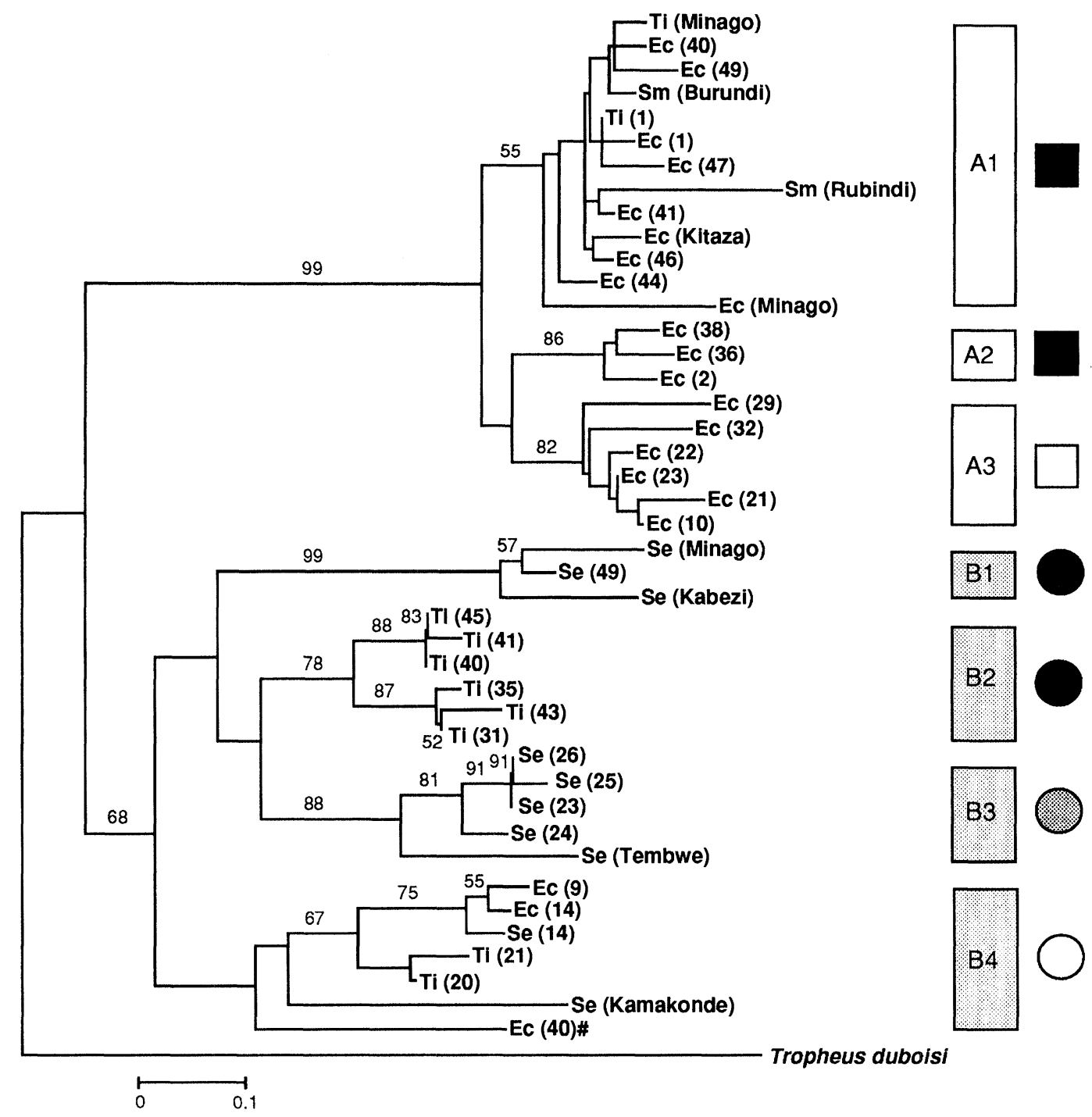

Figure 3. Neighbour-joining tree of the Eretmodini. The distances were corrected for multiple substitutions (Kimura 1980). Gap sites and missing information (insertions and deletions or indels) are ignored in distance estimation; the option 'pairwise-deletion' was used to analyse sequences that contain such sites. Bootstrap values are given on those branches that were obtained in $>50 \%$ of the 1000 replications. Branches are drawn to scale, with the bar representing per cent divergence. The species names are given according to the current taxonomic assignments: Ec $=$ Eretmodus cyanostictus, $\mathrm{Ti}=$ Tanganicodus irsacae, $\mathrm{Se}=\mathrm{Spathodus} \mathrm{erythrodon,} \mathrm{Sm}=$ Spathodus marlieri. Locality names and numbers are given in brackets. Ec (40)\# indicates a Eretmodus that is morphologically distinct from Ec (40). Clade designations (see text) are based on neighbour-joining and parsimony analyses.

\section{DISGUSSION}

\section{(a) The influence of Lake Tanganyika's history on the adaptive radiation}

Allopatric speciation, either through geographic isolation or habitat segregation seems to be the most important mode of intralacustrine speciation for cichlids (e.g. reviewed in Meyer 1993b; but see Schliewen et al. 1994). The age estimates for various endemic Tanganyikan lineages, including the Eretmodini suggest that during the geological history of the lake, when the actual rift formation occurred, cichlids rapidly filled the available niches over the entire lake (e.g. Liem \& Osse 1975; reviewed in Coulter 1991; Cohen 1993; Meyer 1993 b; Snoeks et al. 1994). When, more recently in the Pleistocene, climatic changes resulted in lowered water levels, the single Lake
Tanganyika basin became divided into three paleolakes, probably for many thousands of years (Scholz \& Rosendahl 1988; Tiercelin \& Mondeguer 1991). These fluctuations in level effectively isolated populations of cichlids, including eretmodines, into northern, central, and southern basin populations (figures 1 \& 5). It has been suggested that not only basin subdivision but also minor fluctuations in lake level probably influenced the evolution of the littoral cichlid fauna (Fryer \& Iles 1972; Coulter 1991). Sandy beaches or estuaries that separate rocky shores are supposed to act as barriers to gene flow, by influencing the distribution of genetic variation, and probably speciation, in these fishes (Coulter 1991). Particularly stenotopic and philopatric species like the eretmodine cichlids, that seem to be adapted to living in shallow gravel and rocky shores could have been isolated by small continuous changes 


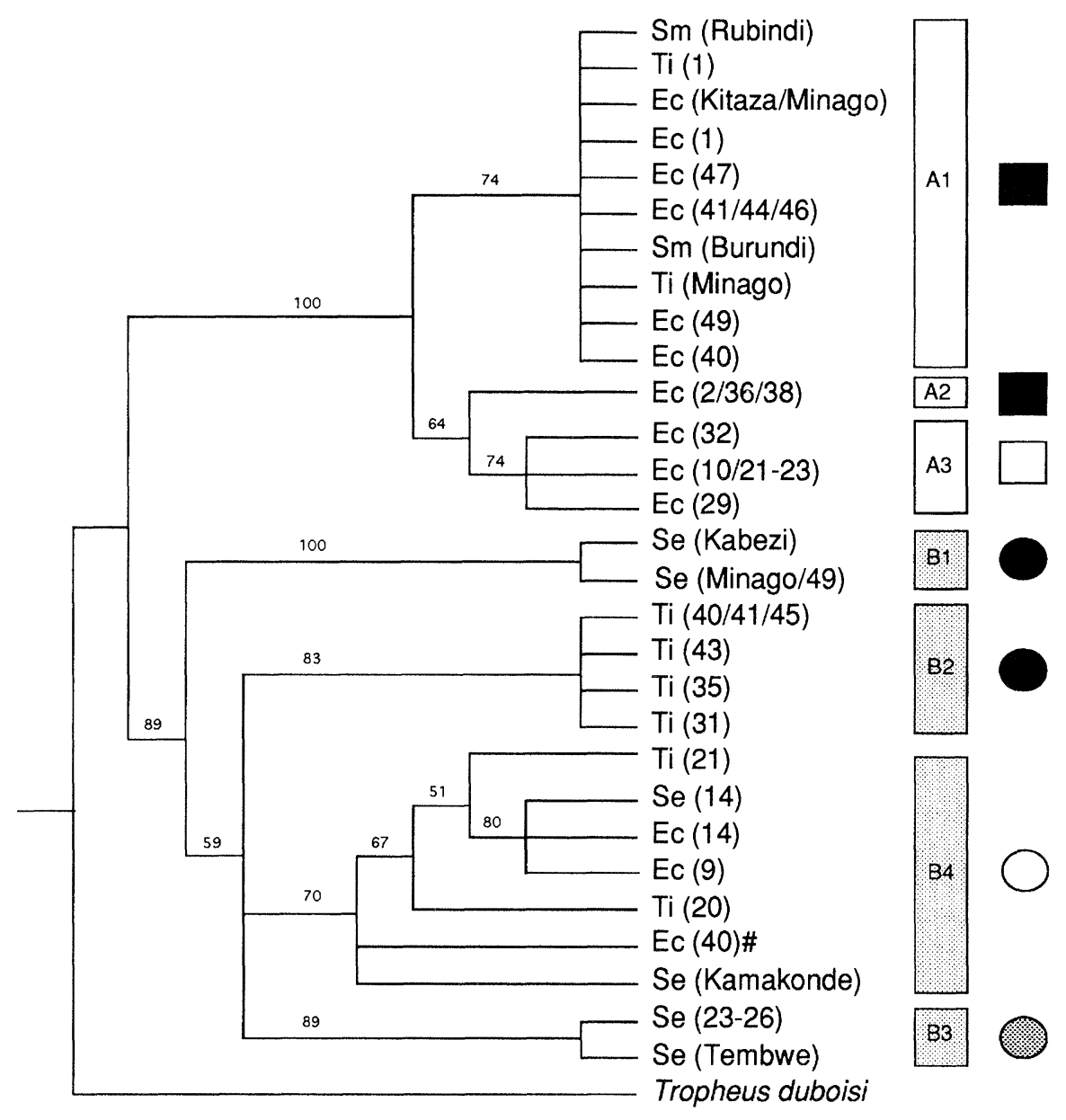

Figure 4. Strict consensus tree constructed from 550 equally parsimonious trees (tree length of 208 steps). Heuristic search with random addition of taxa (10 replications) and transversions were weighed two times over ransitions. Bootstrap (Felsenstein 1985) values from a separate bootstrap analysis are given on those branches that were obtained in $>50 \%$ of the replications (heuristic search, simple addition of taxa, 100 bootstrap replications). This strict consensus tree was not constructed using all specimens in our dataset. Several of the OTUs are represented by a consensus control region sequence of conspecific eretmodines that show identical cytochrome $b$ sequences (authors' unpublished data). The species names are given according to the current taxonomic assignments: $\mathrm{Ec}=$ Eretmodus cyanostictus, $\mathrm{Ti}=$ Tanganicodus irsacae, $\mathrm{Se}=$ Spathodus erythrodon, $\mathrm{Sm}=$ Spathodus marlier. Locality names and numbers are given in brackets. Ec (40)\# indicates a Eretmodus that is morphologicaly distinct from Ec (40). Clade designations (see text) are based on neighbour-joining and parsimony analyses.

in water levels. Changes of water level produce changes in habitats, such as rocky shores, that are patchily distributed along the coastline. If the periods of isolation existed long enough, genetic differences between populations would have been likely to arise by drift, and could result in the formation of new species. However, as shown earlier on the basis of species distributions of Lamprologini (Snoeks et al. 1994), even the huge Malagarazi River delta (figure 1) does not seem to have been a strict barrier for some taxa (figures $5 a, b)$. However, the phenotypic data for lamprologine cichlids need to be compared with future genetic data.

\section{(b) Paleo-limnology and phylogeography}

The evolutionary history of the Eretmodini is strongly related to the geological history of Lake Tanganyika. The data presented here clearly show the effects of fluctuations in water level on the present distribution of genetic variation. Indeed, the dis- tribution of recent Eretmodini mtDNA clades matches quite closely the now-inundated shorelines of the three intermittent Lake Tanganyika paleo-lakes (figure $5 a$, $b)$. The within-lake distribution of all clades, but in particular those of clades A1, A2, and A3, are restricted to the northern, central or southern intermittent lake basins that existed from about 200000 to about 75000 years ago (Scholz \& Rosendahl 1988). The occurrence of genetically distinct clades with restricted distributional patterns and the presence of closely related populations on both sites of the lake (e.g. Spathodus from localities (23-26) and Tembwe, and lineage B4 from around the Kipili Islands and Kamakonde) suggest that major fluctuations of water level in Lake Tanganyika had pronounced effects on speciation, and on the distribution of the cichlids in rocky littoral habitats.

As observed in the genus Tropheus (Sturmbauer \& Meyer 1992), but not in Simochromis (Meyer et al. 1996), our data on sequence divergence indicate that at least two consecutive periods of rapid diversification 
(a)

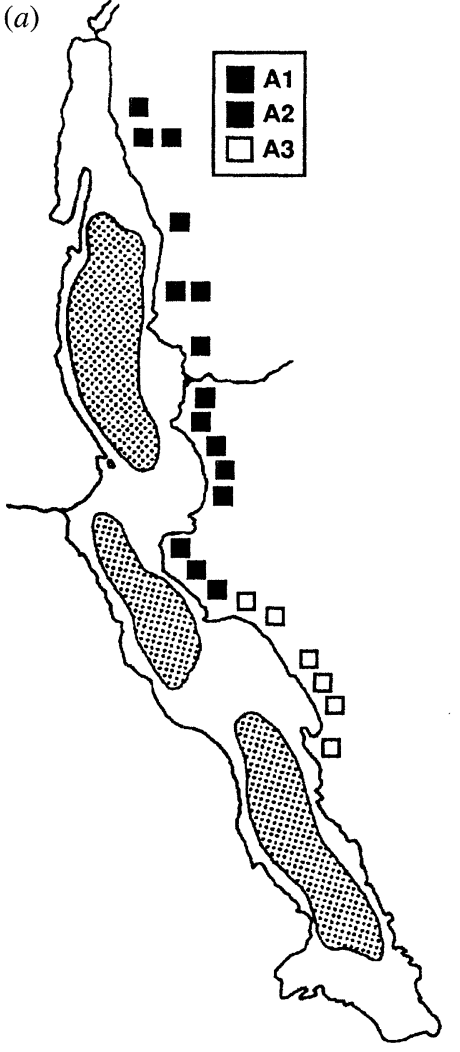

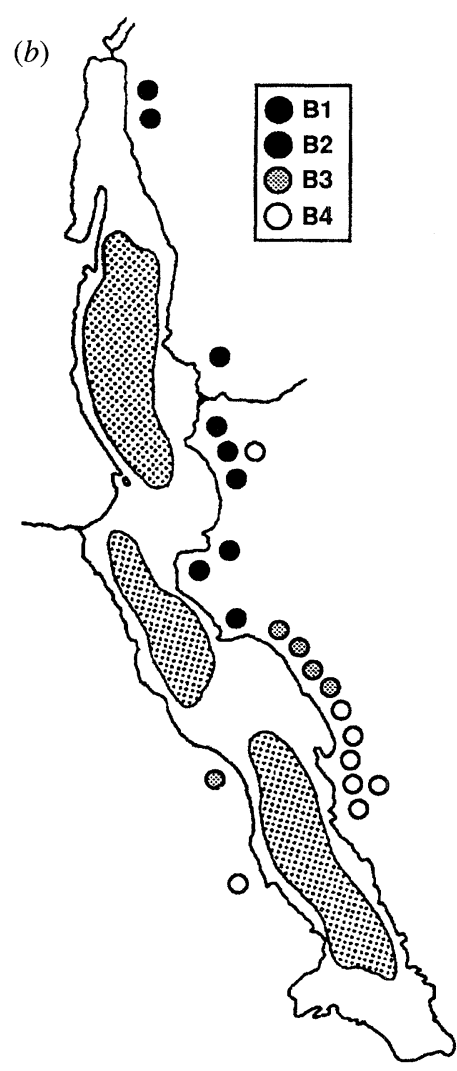

Figure 5. Maps of Lake Tanganyika showing the mtDNA distribution of the studied Eretmodini. The symbols indicate genetically distinct lineages based upon the phylogenetic analyses (see figures 3 and 4). (a) Intralacustrine distribution of mtDNA haplotypes belonging to lineages A1, A2 and A3. (b) Intralacustrine distribution of mtDNA haplotypes that belong to lineages B1, B2, B3 and B4. Each map shows the three separate paleo-lakes that follow the present 600 depth contour (Tercelin \& Monteguer 1991). Localities where two identical symbols appear (for example, locality 1 in figure $5 a$; see also figure 1 ) indicate that individuals with different tooth morphology, and hence different generic assignment, have been collected and sequenced.

occurred during the evolutionary history of Eretmodini clades (figure 3 ). This seems in particular to be the case for the A-lineage (figure 3), whereas the ages of the Bclades seem to be older and more varied. B-lineage eretmodine cichlids may have originated somewhat earlier, and for different reasons, than did the members of the A mtDNA eretmodine lineage. Just as in Tropheus populations(Sturmbauer \& Meyer 1992), the Eretmodini populations along some stretches of the Tanganyika coastline appear to be effectively isolated from each other, even if they are separated by only a few kilometres (figures 3, 4, \& 5). However, one mtDNA lineage of Tropheus was found lake-wide (Sturmbauer \& Meyer 1992). In contrast, all the genetically distinct Eretmodini lineages seem to have restricted distributions along the coastline (figure 5). The phylogeographic pattern reveals only two examples of allopatric populations that share an identical haplotype (Tanganicodus from localities 40 and 45; Spathodus from localities 23 and 26). In these instances the localities are only about 20 kilometer apart. This suggests that gene flow of mtDNA haplotypes might be low even between geographically nearby populations. As no more than one individual per locality has been analysed, we do not know if these two populations are fixed for these mtDNA haplotypes.

\section{(c) MtDNA phylogeny and the taxonomy of the \\ Eretmodini}

Morphology-based taxonomy places the Eretmodini in their respective genera mainly on the basis of dental features (Poll 1986). The major mtDNA clades contain mostly morphologically homogeneous groups. However, our mtDNA phylogeny is in partial conflict with the current generic classification. For example Lineage A is mainly constituted of specimens that morphologically correspond to $E$. cyanostictus as defined by Poll (1986). However, clade Al also contains $T$. irsacae (from localities 1 and Minago), S. marlieri (Rubindi and another locality in Burundi). In addition, unpublished S. marlieri sequences (C. Sturmbauer, personal communication) also fell within the Al clade. Clade B4 contains the three genera, as they are currently defined. Tanganicodus irsacae are found in several of the mtDNA clades. However, these Tanganicodus can be differentiated on the basis of morphological features. Those found in Minago and locality 1 resemble the fishes from the type locality (Uvira, north Zaire), and can be distinguished from those south of the Malagarazi delta by the presence of a dark spot in the soft rayed part of the dorsal fin, and by their colour pattern. The occurrence of two distinct Eretmodus cyanostictus mtDNA 
haplotypes that belong to clade $\mathrm{Al}$ and $\mathrm{B} 4$ at locality 40 is supported by morphological characters (Rüber $e t$ al. in preparation). Because the type locality of $E$. cyanostictus is Kinyamkolo (= Mpulungu) in Zambia, the Eretmodus specimens from localities 9, 14 and 40 (clade B4) may represent the genuine Eretmodus cyanostictus. The occurrence of supposedly genuine $E$. cyanostictus at locality 40 , which is separated by more than $200 \mathrm{~km}$ from the other members of clade B4, may represent a remnant population of a previously more widespread clade.

MtDNA phylogenies do not necessarily reflect the true species phylogeny. Lineage sorting and the retention of ancestral polymorphisms can result in the occurrence of mitochondrial poly- and paraphyly between biological species (Moran \& Kornfield 1993, 1995). Although this may be the case for the extremly young mbuna cichlids from Lake Malawi, it is not likely to be true for the Eretmodini because they are considerably older than the Malawi and Victoria cichlids (Meyer et al. 1990; Meyer 1993b). Another explanation for the occurrence of mtDNA polymorphisms across species boundaries is introgressive hybridization after secondary contact (e.g. Dowling \& DeMarais 1993). Parental-care patterns and mating systems differ between Spathodus marlieri and the representatives of the two other genera. However, no relevant information is available on the breeding biology of Spathodus erythrodon (Kuwamura et al. 1989) and there are no studies that allow us to refute the possibility of introgressive hybridization. To test this hypothesis it will be necessary to investigate nuclear markers and to conduct breeding experiments with Eretmodus, Spathodus and Tanganicodus from the different mtDNA clades.

Our data suggest that the species originally assigned to three different genera represent several more lineages that are genetically and morphologically distinct. Because several genetically distinct lineages are found within each of the studied genera, the suggestion that Spathodus and Tanganicodus are derived monophyletic lineages, with Eretmodus as their ancestral sister lineage (Liem 1979), needs to be reexamined. Therefore it is our intention to study other molecular markers, as well as morphological characters, to establish a phylogenetically based generic classification of the Eretmodini. Our results suggest that the shape of the oral jaw teeth, which is the main morphological feature used for this classification of the Eretmodini, may be highly variable, homoplasious and unreliable for taxonomic purposes. The differences in dental morphology (e.g. the position of the mouth and the morphology of the dental arcade) among these fishes, and their relative gut lengths, are related to differences in feeding behaviour (Yamaoka 1985, 1987; Yamaoka et al. 1986). Interestingly, sympatric Eretmodini taxa are usually species-pairs that evolved from one of the two most basal branches within the group. Sympatric taxa seem to differ morphologically, and hence ecologically, pointing to the possibility that ecological diversification may be important for speciation and niche partitioning and for the coexistence of two sympatric lineages. In most of the cases that we examined, the species-pairs consist of one species with a typical Eretmodus-like dentition and the other with a Tanganicodus- or Spathodus-like dentition. Evolution of these dental characteristics might suggest that competition for food between members of the Eretmodini has been a driving force for the multiple independent occurrence of similar trophic specializations (L. Rüber et al., unpublished data).

We are grateful to the Governments of the Republic of Burundi (Professor Dr. Ntakimazi, University of Burundi) and Tanzania (Professor Dr. Bwathondi, Tanzanian Fisheries Research Institute, Dar es Salaam) for granting us research permits to collect fishes on Lake Tanganyika. We also thank Heinz H. Büscher for providing us with specimens from Zaire (Tembwe and Kamakonde) and Luc 'Tuur' De Vos for the samples from Rubindi. Christian Sturmbauer, Thierry Backeljau, Ole Seehausen and Koen Martens provided helpful comments on the manuscript. During this study, L.R. was supported by an ERASMUS-grant, A.M. was supported by National Science Foundation grants (BSR9119867 and BSR-9107838); A.M. and E.V. by a NATO collaboration grant (CRG-910911) and E.V. was funded by grants of the Belgian Fund for Joint Basic Research (F.K.F.O. program 2.0004.90 and F.K.F.O.M.I.30-35).

\section{REFERENGES}

Avise, J. C., Arnold, J., Ball, R. M., Bermingham, E., Lamb, T., Neigel, J. E., Reeb, C. A. \& Saunders, N. C. 1987 Intraspecific phylogeography: the mitochondrial DNA bridge between population genetics and systematics. $A$. Rev. Ecol. Syst. 18, 489-522.

Bowers, N., Stauffer, J. R. \& Kocher, T. D. 1994 Intra- and interspecific mitochondrial DNA sequence variation within two species of rock-dwelling cichlids (Teleostei: Cichlidae) from Lake Malawi, Africa. Molec. Phylogenet. Evol. 3, 75-82.

Brichard, P. 1989 Cichlids of Lake Tanganyika. Neptune City: TFH Puplications.

Brooks, J. L. 1950 Speciation in ancient lakes. Q. Rev. Biol. 25, 30-60; 131-176.

Brown, W. M., George, M. \& Wilson, A.C. 1979 Rapid evolution of animal mitochondrial DNA. Proc. natn. Acad. Sci. U.S.A. 76, 1967-1971.

Cohen, A. S., Soreghan, M.J. \& Scholz, G. A. 1993 Estimating the age of formation of lakes: an example from Lake Tanganyika, East African Rift system. Geology 21, 511-514.

Coulter, G. W. 1991 Zoogeography, affinities and evolution with special regard to the fishes. In Lake Tanganyika and its life (ed. G. W. Coulter), pp. 275-305. Oxford University Press.

DeSalle, R., Freedman, T., Prager, E. M. \& Wilson, A. C. 1987 Tempo and mode of sequence evolution in mitochondrial mtDNA of Hawaiian Drosophila. J. molec. Evol. 26, 157-164.

Dominey, W.J. 1984 Effect of sexual selection and life history on speciation: species flocks in African cichlids and Hawaiian Drosophila. In Evolution of fish species flocks (ed A. A. Echelle \& I. Kornfield), pp. 231-249. Orono: University of Maine Press.

Dowling, T. E. \& DeMarais, B. D. 1993 Evolutionary significance of introgressive hybridization in cyprinid fishes. Nature, Lond. 362, 444-446.

Felsenstein, J. 1985 Confidence limits on phylogenies: an approach using the bootstrap. Evolution 39, 783-791.

Fryer, G. \& Iles, T. D. 1972 The cichlid fishes of the great lakes 
of Africa: their biology and evolution. Edinburgh: Oliver \& Boyd.

Futuyma, D. J. 1986 Evolutionary biology. Sunderland, Massachusetts: Sinauer Associates.

Greenwood, P. H. 1964 Explosive evolution in African lakes. Proc. R. Instn Gt Br. 40, 256-269.

Kimura, M. 1980 A simple method for estimating the evolutionary rate of base substitutions through comparative studies of nucleotide sequences. J. molec. Evol. 16, $111-120$

Klein, D., Ono, H., O’hUigin, G., Vincek, V., Goldschmidt, T. \& Klein, J. 1993 Extensive MHG variability in cichlid fishes of Lake Malawi. Nature, Lond. 364, 330-334.

Kocher, T. D., Thomas, W. K., Meyer, A., Edwards, S. V., Pääbo, S., Villablanca, F. X. \& Wilson, A. C. 1989 Dynamics of mitochondrial DNA evolution in animals: amplification and sequencing with conserved primers. Proc. natn. Acad. Sci. U.S.A. 86, 6196-6200.

Kocher, T. D., Conroy, J. A., McKaye, K. R. \& Stauffer, J. R. 1993 Similar morphologies of cichlid fishes in Lake Tanganyika and Malawi are due to convergence. Molec. Phylogenet. Evol. 2, 158-165.

Konings, A. 1988 Tanganyika cichlids. Zevenhuizen, Holland, Herten Germany: Verduijn Cichlids and Lake Fish Movies.

Kumar, S., Tamura, K. \& Nei, M. 1993 Molecular evolutionary genetics analysis (MEGA version 1. 01). The Pennsylvania State University, University Park, Pensylvania 16802.

Kuwamura, T., Nagoshi, M. \& Sato, T. 1989 Female-tomale shift of mouthbrooding in a cichlid fish, Tanganicodus irsacae, with notes on breeding habits of two related species in Lake Tanganyika. Env. Biol. Fish. 24, 187-198.

Liem, K. F. 1979 Modulatory multiplicity in the feeding mechanism in cichlid fishes, as exemplified by the invertebrate pickers of Lake Tanganyika. J. Zool. 189, 93-125.

Liem, K. F. \& Osse, J. W. M. 1975 Biological versatility, evolution, and food resource exploitation in African cichlid fishes. Am. Zool. 15, 427-454

Martens, K., Coulter, G. \& Goddeeris, B. 1994 Speciation in ancient lakes -40 years after Brooks. In Speciation in ancient lakes (ed. K. Martens, B. Goddeeris \& G. Coulter), Adv. Limnol. 44, 75-96.

Meyer, A. 1993 a Evolution of mitochondrial DNA in fishes. In Biochemistry and molecular biology of fishes (ed. P. W. Hochachka \& T. P. Mommsen), vol. 2, pp. 1-38. London: Elsevier.

Meyer, A. $1993 b$ Phylogenetic relationships and evolutionary processes in East African cichlid fishes. Trends Ecol. Evol. 8, 279-284.

Meyer, A., Kocher, T. D., Basasibwaki, P. \& Wilson, A. C. 1990 Monophyletic origin of Lake Victoria cichlids suggested by mitochondrial DNA sequences. Nature, Lond. 347, 550-553.

Meyer, A., Knowles, L. \& Verheyen, E. 1996 Widespread distribution of mitochondrial haplotypes in rock-dwelling cichlid fishes from Lake Tanganyika. Molec. Ecol. 5, 341-350.

Meyer, A. Morrissey, J. M. \& Schartl, M. 1994 Recurrent origin of a sexually selected trait in Xiphophorus fishes inferred from a molecular phylogeny. Nature, Lond. 368, $539-542$.

Moore, J.E. S. 1903 The Tanganyika problem. London: Hurst \& Blackett.

Moran, P. \& Kornfield, I. 1993 Retention of ancestral polymorphism in the mbuna species flock (Teleostei: Cichlidae) of Lake Malawi. Molec. Biol. Evol. 10, 10151029 .
Moritz, C., Dowling, T. E. \& Brown, W. M. 1987 Evolution of animal mitochondrial DNA: relevance for population biology and systematics. A. Rev. Ecol. Syst. 18, 269-292.

Owen, R. B., Crossley, R., Johnson, T. C., Tweddle, D., Kornfield, I., Davison, S., Eccles, D. H. \& Engstrom, D. E. 1990 Major low levels of Lake Malawi and their implications for speciation rates in cichlid fishes. Proc. $R$. Soc. Lond. B 240, 519-553.

Poll, M. 1951 Histoire du peuplement et origine des éspèces de la faune ichthyologique du Lac Tanganika. Ann. Soc. $r$. zool. Malac. Belg. 81, 111-140

Poll, M. 1986 Classification des Cichlidae du lac Tanganika: Tribus, Genres et Espèces. Acad. royale de BelgiqueMém. Sci., Coll. $8^{\circ}-2^{\circ}$ ser. tome XLV, fasc. 2, 1-163.

Ribbink A.J. 1986 Species concept, sibiling species and speciation. Ann. Mus. r. Afr. Centr. Sci. Zool. 251, 109-116.

Ribbink A.J. 1994 Alternative perspectives on some controversial apsects of cichlid fish speciation. In Speciation in ancient lakes (ed. K. Martens, B. Goddeeris \& G. Coulter), Adv. Limnol. 44, 101-125.

Saccone, C., Attimonelli, M. \& Sbisá, E. 1987 Structural elements highly preserved during the evolution of the Dloop-containing region in vertebrate mitochondrial DNA. J. molec. Evol. 26, 205-211.

Saitou, N. \& Nei, M. 1987 The neighbor-joining method: a new method for constructing phylogenetic trees. Molec. Biol. Evol. 4, 406-425.

Schliewen, U. K., Tautz, D. \& Pääbo, S. 1994 Sympatric speciation suggested by monophyly of crater lake cichlids. Nature, Lond. 368, 629-632.

Scholtz, G. \& Rosendahl, B. 1988 Low lake stands in Lakes Malawi and Tanganyika, east Africa, delineated with multifold seismic data. Science, Wash. 240, 1645-1648.

Snoeks, J., Rüber, L. \& Verheyen, E. 1994 The Tanganyika problem: taxonomy and distribution patterns of its ichthyofauna. In Speciation in ancient lakes (ed. K. Martens, B. Goddeeris \& G. Coulter), Adv. Limnol. 44, 357-374.

Sturmbauer, G. \& Meyer, A. 1992 Genetic divergence, speciation and morphological stasis in a lineage of African cichlid fishes. Nature, Lond. 358, 578-581.

Sturmbauer, C. \& Meyer, A. 1993 Mitochondrial phylogeny of the endemic mouthbrooding lineages of cichlid fishes from Lake Tanganyika in Eastern Africa. Molec. Biol. Evol. 10, 751-768.

Sturmbauer, C., Verheyen, E. \& Meyer, A. 1994 Mitochondrial phylogeny of the Lamprologini, the major substrate spawning lineage of cichlid fishes from Lake Tanganyika in Eastern Africa. Molec. Biol. Evol. 11, 691-703.

Sültmann, H., Meyer, W. E., Figuero, F., Tichy, H. \& Klein, J. 1995 Phylogenetic analysis of cichlid fishes using nuclear DNA markers. Molec. Biol. Evol. 12, 1033-1047.

Swofford, D. L. 1993 Phylogenetic analysis using parsimony (PAUP version 3. 1. 1. Champaign: Illinois Natural History Survey.

Tiercelin, J. J. \& Mondeguer, A. 1991 The geology of the Tanganyika Trough. In Lake Tanganyika and its life (ed. G. W. Coulter), pp. 7-48. Oxford University Press.

Yamaoka, K. 1985. Intestinal coiling pattern in the epilithic algal-feeding cichlids (Pisces, Teleostei) of Lake Tanganyika, and its phylogenetic significance. Zool. J. Linn. Soc. 84, 235-261.

Yamaoka, K. 1987 Comparative osteology of the jaw of algal-feeding cichlids (Pisces, Teleostei) from Lake Tanganyika. Rpts Usa Mar. Biol. Institut., Kochi Univ. 9, 87-137.

Yamaoka, K., Hori, M. \& Kuratani, S. 1986 Ecomorphology of feeding in goby-like cichlid fishes in Lake Tanganyika. Physiol. Ecol. Jap. 23, 17-29. 